\title{
MOQI: ASENTAMIENTO INCA EN LA CABECERAS DE LA CUENCA LOCUMBA
}

\author{
Jesús Gordillo Begazo \\ Aldo Bolaños Baldassi ${ }^{3}$
}

\section{RESUMEN}

El presente trabajo se enmarca dentro del Proyecto de Investigación Moqi-Perú temporada 2012. Consideramos al proyecto una opción para conocer la presencia del Imperio Inca en los valles de Tacna y su relación con las estructuras e instituciones instauradas por la capital cusqueña en los territorios conquistados, fuera de la esfera inmediata de la capital.

En términos generales, con el inicio de este proyecto pretendemos determinar las características formales de la arquitectura del sitio arqueológico y sus posibles diferencias entre Moqi Alto y Moqi Bajo y definir la temporalidad del sitio arqueológico, su función y las relaciones económicas en el contexto interno, y su articulación con el estado Inka

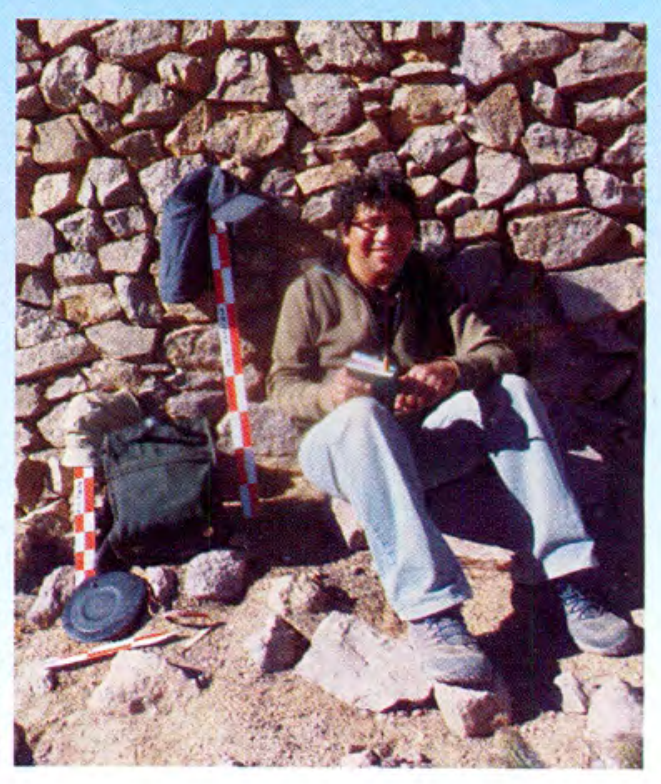
luego conocer las características demográficas de la población y sus relaciones sociales, a través del componente mortuorio en Moqi Alto y Moqi Bajo.

\section{Metodología de investigación arqueológica en Moqi Perú}

En lo que va la temporada de investigación 2012, se han desarrollado cinco frentes de trabajo de campo, dos de gabinete y laboratorio, y los análisis de laboratorio de muestras para fechado y análisis de isotopos en los EE. UU. Se ha realizado una prospección arqueológica de los valles de

'Convenio de Cooperación Interinstitucional entre la Universidad Privada de Tacna y el Institute For Research-University OfCalifornia-Los Ángeles-USA. Director del proyecto Moqi Perú, Temporada 2012.

Jefe de campo para el análisis del componente arquitectónico.
Cambaya y Borogueña, el mapeo de Moqi Alto y Moqi Bajo, la recolección de material cultural de superficie, las excavaciones en los recintos habitacionales y en los cementerios y el análisis del componente arquitectónico del sector Moqi Alto.

\section{Algunos resultados del componente arquitectónico}

El análisis del componente arquitectónico de Moqi Alto determinó la presencia de tres terrazas constructivas principales que modelaron el cerro Moqi y siete 

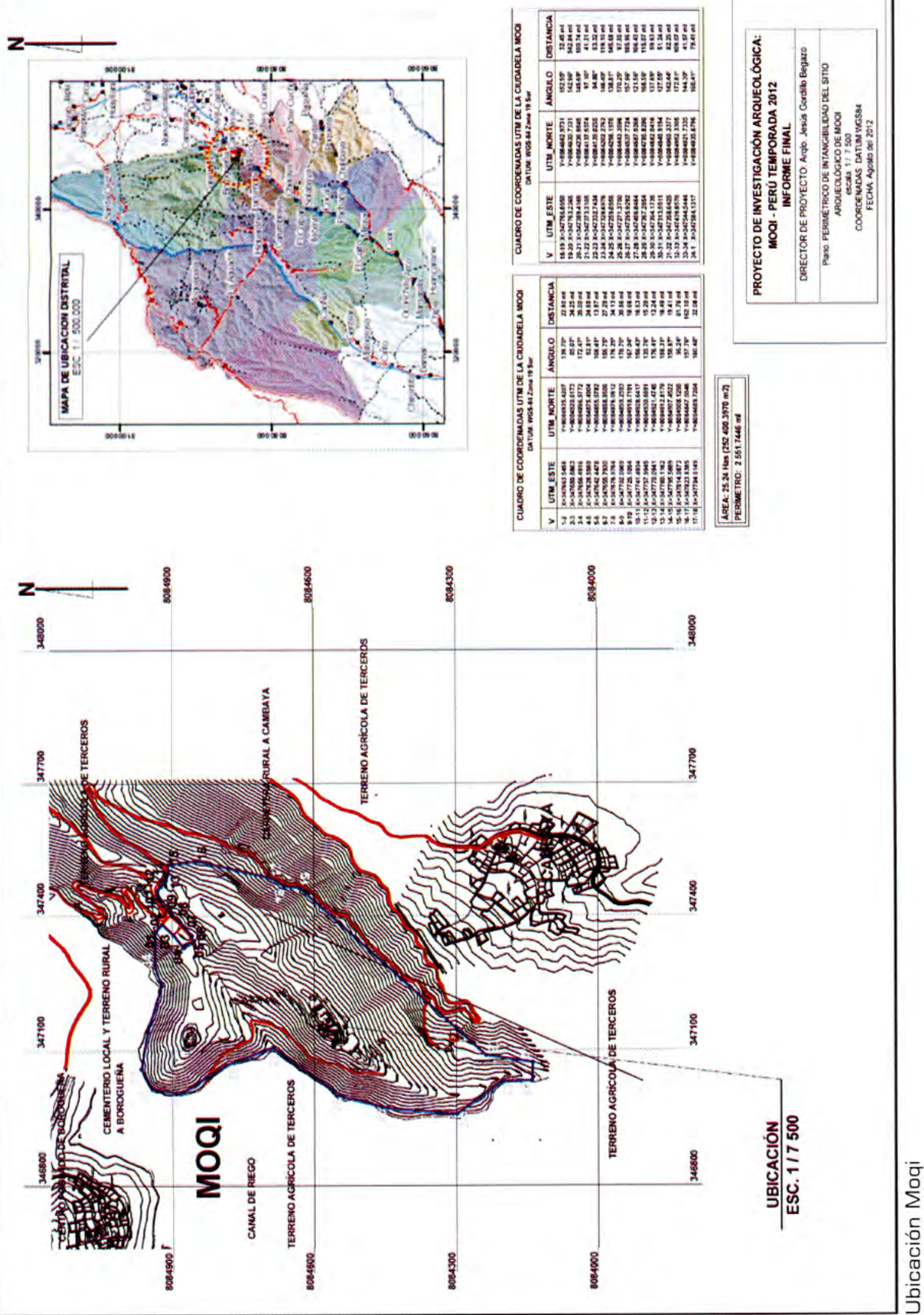
poblaciones locales fueron integradas a las estructuras políticas, económicas e ideológicas del Inca, en cuyo proceso las provincias vieron afectados sus modos de vida de origen.

La explicación de este proceso de anexión de territorios al estado Inca, se realizó bajo los sistemas de control hegemónico (gobierno de menor visibilidad e inversión estatal: bienes muebles, correspondiente a circunstancias donde la presencia del Estado no se materializa en obras de infraestructura, sino solamente a través de objetos de prestigio en context os domésticos y ceremoniales y la asociación espacial con centros administrativos incaicos) y control territorial (fuerte intervención del aparato administrativo del Estado en las provincias: recursos agrícolas, mineros, marítimos, espacios sagrados, centros administrativos, redes viales, tambos, sistemas de irrigación, andenerías, colcas) (Williams, 2009: 616 617).

Las explicaciones tradicionales sobre las relaciones de los valles de Tacna y de Arica con el estado Inca, indicaban un control indirecto por parte de los reinos altiplánicos ya anexados al estado, y que no respondía a un manejo de interés administrativo directo desde el Cusco (Gordillo 2000; Hidalgo y Santoro 2001 ; Muñoz 1989, 1998; Muñoz y Chacama 1993; Muñoz, Chacama y Espinosa 1987; Romero 1999; Santoro 1983; Schiappacasse y Niemeyer 1989]. Sin embargo, al hacer un repaso de las evidencias arqueológicas en la región de Tacna (incluye los trabajos del Proyecto Qhapaq Nan), éstas muestran un conjunto de componentes Inca que delatan una importante inversión estatal e interés en estos territorios, siendo el sitio de Moqi uno de los más importantes de los Valles
Occidentales (Flores Espinoza de Lumbreras 1969, 1983; Gordillo 1993, 1996, 2000, 2006; Romero 2005; Santoro et al. 2004; Trimborn et al. 1975; Uhle 1919; Vela 2004]. Los efectos de este proceso político en la región de Tacna recién comienzan a evaluarse con mayor precisión.

Uno de los propósitos de nuestro proyecto de investigación, en parte es entender y tratar de explicar el sitio Moqi en el marco de los antecedentes de la arqueología de Tacna, en especial desde sus sociedades locales tardías (1,100 - 1445 años d.C $)$ hasta la ocupación Inca. El mayor despliegue de infraestructura productiva se inicia precisamente con los desarrollos locales tardíos, representados por los estilos costeros de Chiribaya, San Miguel, Pocoma y Gentilar. En la zona pre cordillerana, se desarrolló el estilo local de Sitajara (Gordillo, 1996, 2000J. Sobre estas instalaciones los Incas impulsaron inversiones de mayor envergadura, en especial en las cabeceras de lastres c u e n c a s hidrográficas de los valles de Tacna (Locumba, Sama y Caplina), entre los 2,500 a 3,500 msnm, donde existen complejos sistemas de andenes, infraestructura hidráulica, red vial e instalaciones arquitectónicas administrativas, como los casos de Huancarane, Qhile y Kanamarca en Susapaya y Moqi en Cambaya Borogueña. En la zona del altiplano regional, prevalecen la presencia de tambos, kallancas y caminos que bajan desde la cuenca del Titicaca e indistintamente penetran por las cabeceras de las tres cuencas. 
En los valles de la costa y en el litoral, el Estado impulsó la producción de zapallo. frijol, achira, maíz, ají, algodón y frutales; y en el litoral la explotación del "guano de isla" fue la principal actividad extractiva, seguida de la pesca y la obtención de otros recursos como moluscos, crustáceos y cochayuyo. Los mecanismos de producción y distribución de todos estos bienes y productos, al parecer habría generado todo un sistema de tráfico interregional vertical y longitudinal, teniendo como ejemplos a: "Sama La Antigua" en el valle de Sama (Trimborn et al 1975), el sitio "Cerro Los Hornos" (Vela, 2004) y "Punta Picata" (Gordillo et al 2011) en el litoral. Sama La Antigua es un gran centro administrativo que al parecer articula la costa con el altiplano, y los sitios Los Hornos y Punta Picata están relacionados directamente con el control y la circulación de los productos marinos. Por su parte, los sitios de Qhile, Kanamarca y Huancarane, son de mayor envergadura, ubicados en la cabecera de la $\mathrm{CH}$ de Sama, en el sector de Susapaya. Son complejos urbanos asociados a una impresionante infraestructura de andenes, conectados con la red vial que baja del sector de llave (cuenca occidental del Lago Titicaca) y se dirige hacia Sama y Caplina. En este sector sobresalen la kallanca de Qhile y el complejo de andenes de Kanamarca.

En la cabecera de la $\mathrm{CH}$ de Locumba, entre los ríos Cambaya y Borogueña, se u b i c a Moqi, que es uno de los sitios Inca más complejos de los valles de Tacna: Moqi. El sitio Moqi, objeto de estudio de nuestro proyecto (temporadas 2012), presenta dos sectores bien definidos que los hemos denominado Moqi Alto y Moqi Bajo, con diferencias y recurrencias bien marcadas, ya sea en su arquitectura, cerámica y ubicación estratégica. Buscamos ampliar el conocimiento de las funciones que cumplieron ambos sectores, las relaciones entre su población y sobre todo su vínculo económico, social y cultural con el Estado Inca. Moqi, parece representar un clásico modelo de "centro de control administrativo" de los espacios productivos de los valles de Cambaya y Borogueña, instalado por una élite demandante de las políticas del Estado Inca. La complejidad arquitectónica y espacial de Moqi Alto, contrasta con la arquitectura más modesta de Moqi Bajo, lo que nos hace pensar en una función diferente y probablemente complementaria. La temporada 2013, también busca conocer este sistema de circulación a través del análisis de la arquitectura, depósitos, cerámica y cementerios.

\section{El análisis arquitectónico de Moqi Alto}

De acuerdo al análisis arquitectónico preliminar realizado en Moqi Alto, al parecer este sector presenta una planificación integral que fue realizada previamente a la construcción del sitio y que se expresa en un proceso de adecuación de las laderas y la angosta planicie superior, mediante el corte del terreno siguiendo las curvas de nivel tanto en dirección longitudinal como transversal al sitio arqueológico. Los recintos y espacios abiertos se distribuyeron en las terrazas resultantes agrupándose hasta en siete (07) sectores aislados unos de otros por muros separadores y terrazas. La presencia de materiales cerámicos Sitajara I en los rellenos constructivos, especialmente notorios en el lado Oeste del Sector II T1, sugiere la presencia de una ocupación previa. El registro de cerámica Inca en los rellenos del mortero del Sector 


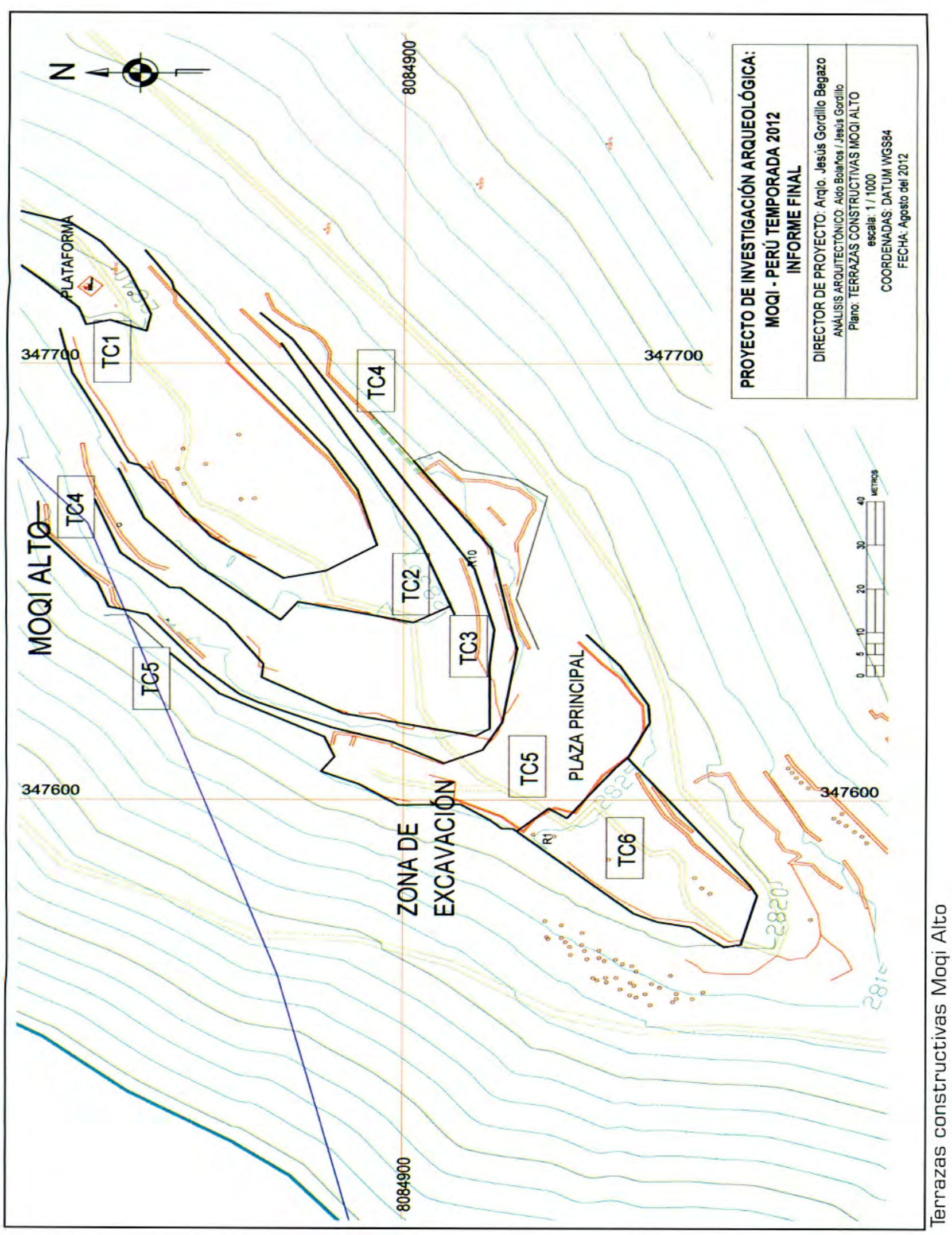




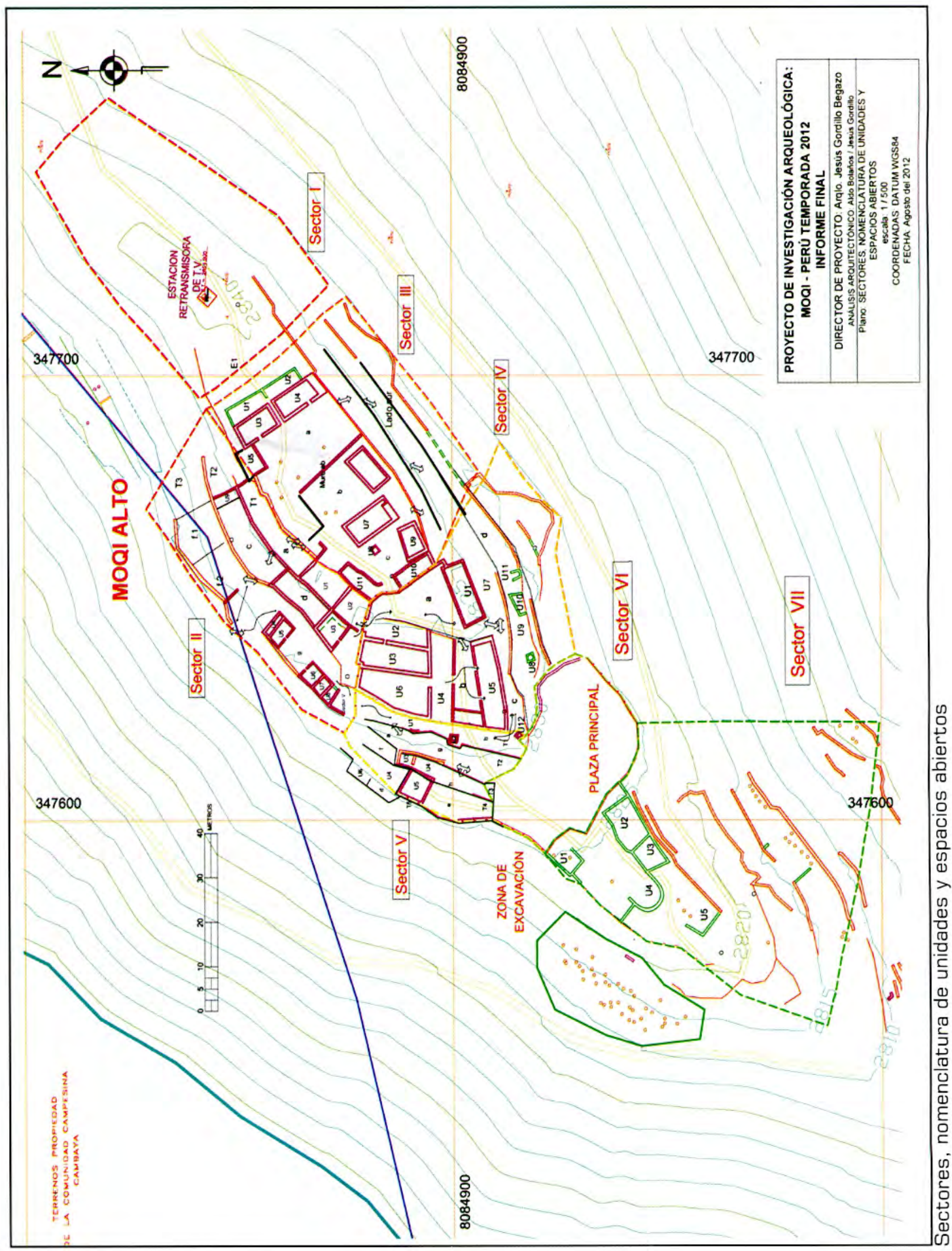


III (Muro ab) implican la posibilidad de una remodelación del sitio durante la ocupación Inca del sitio.

Se construyeron tres (03) terrazas principales que rodeaban todo el cerro y que se usaron como zonas de circulación de un sector a otro, conectándose por pasadizos, vanos y rampas. Se agregaron nuevas terrazas con el fin de producir nuevos espacios para albergar las estructuras necesarias a cada sector. Las terrazas son la base del sistema de circulación interna del sitio. Los muros de contención revelan el uso de dos tipos de aparejo (Aparejo 1 y Aparejo 2). El aparejo 2 , de un mejor aspecto, se caracteriza por estar en las zonas más visibles del sitio y pudo tener una función estética. Ambos tipos de aparejo se distribuyen por paños en algunos de los muros de contención y se debe profundizar el estudio a fin de saber si implicaron a g $r$ e g a d o s estructurales diferenciados según el grupo social constructor. En general, aparte del acabado, los muros muestran técnicas de "adosamiento de las piedras similares".

Las edificaciones se hicieron siguiendo una misma técnica general a todo el $s$ i t i o. Muros continuos con tres esquinas amarradas y una adosada. No se ha detectado que las esquinas adosadas estén siempre en una determinada esquina sino, al parecer, se escogieron estas indiscriminadamente. Los muros elevados gruesos, especialmente en los sectores III y IV, fueron de doble paramento con relleno y los muros delgados de doble paramento sin relleno. El aparejo para el total de los recintos cerrados es del tipo 1 , irregular sin hiladas, de bloques semi canteados y piedra de campo, de tamaño pequeño, mediano y grande y unido por

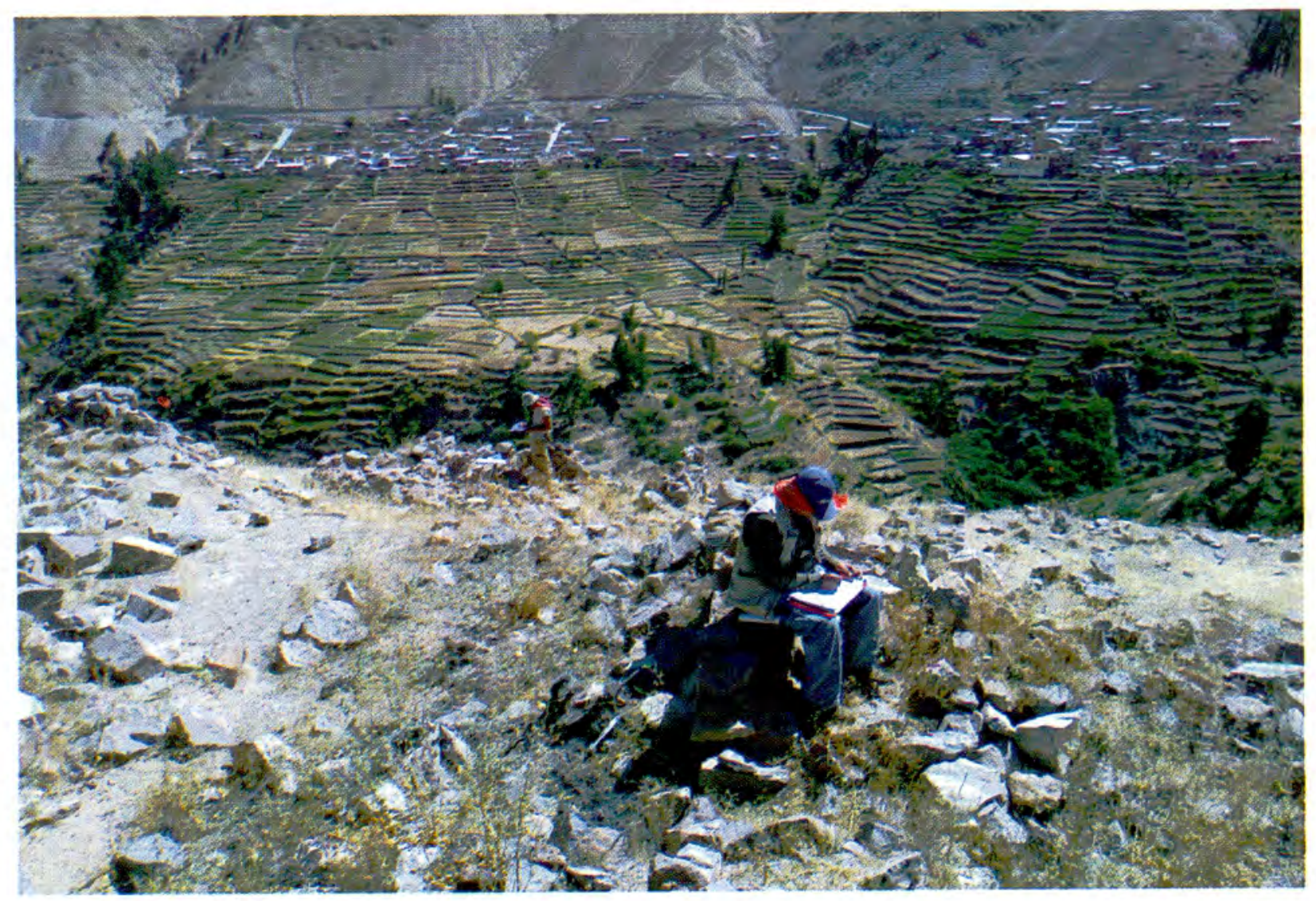

Moqi Alto, sector II 


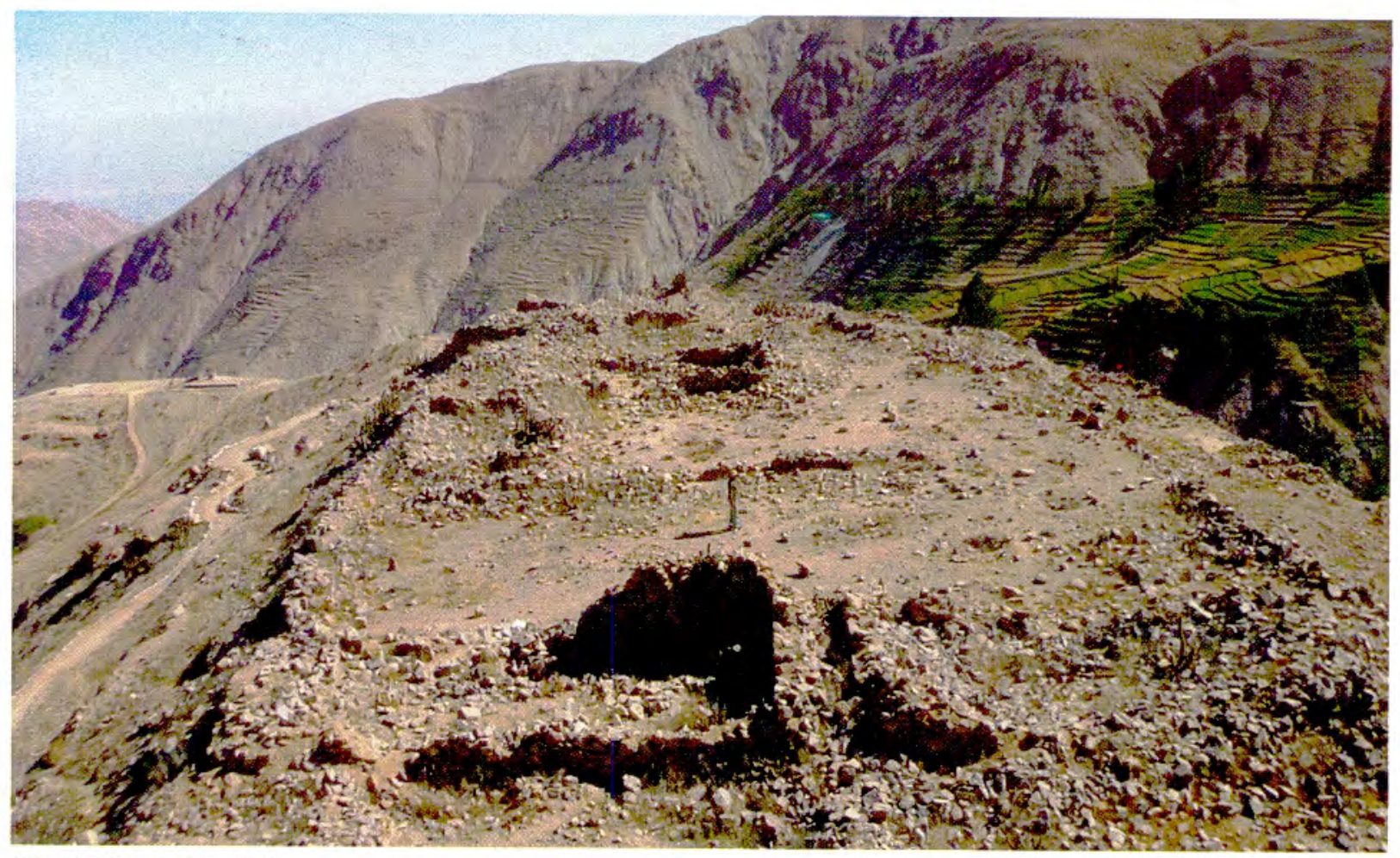

Moqi alto sector III.

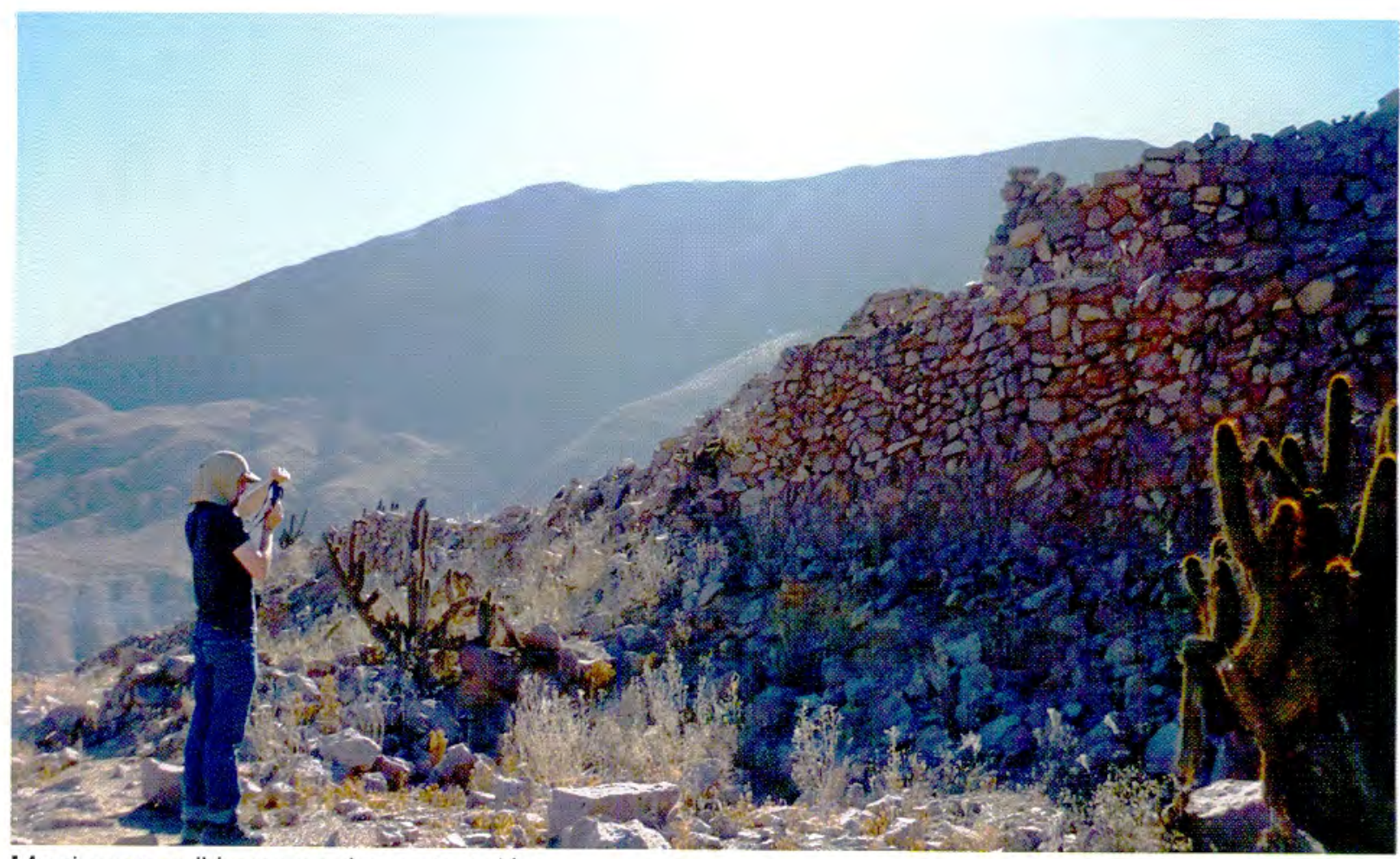

Moqi sector IV, muros de contención. 
mortero.Las piedras utilizadas corresponden a las formaciones geológicas del lugar aunque aparecen algunas piedras pulidas en los muros y que parecen haber pertenecido a batanes 0 grandes molederas. En general, cada sector, se organiza en base al agrupamiento de recintos $\mathrm{c}$ e $\mathrm{r} r$ a d o s alrededor de un espacio abierto. En el caso de las terrazas, especialmente el Sector II $y$ el IV se disponen en una secuencia lineal entre ambos tipos de estructuras arquitectónicas. Este tipo de patrón arquitectónico es coincidente con muchos otros sitios incas de los Andes Centrales.

La presencia de una hornacina trapezoidal en uno de las pocas secciones de muros que aún quedan en pie en el sitio (Sector III U4), también coincidiría con el estilo arquitectónico inca. La presencia de cerámica Sitajara e Inca en los rellenos constructivos así como en los muros indican que los constructores de Moqi Alto removieron los restos de una ocupación previa, no sabemos si anterior a los incas o que hubo una remodelación durante la misma presencia incaica en el sitio. Una gran cantidad de cerámica inca en la superficie de Moqi Alto, confirma que el sitio fue ocupado por ellos.

\section{Conclusión preliminar}

Inferimos finalmente que Moqi Alto fue una construcción unitaria, siguiendo una secuencia constructiva integrada de acuerdo a un diseño previo y la aplicación de una tecnología constructiva homogénea. Todos estos hechos son coincidentes con los patrones arquitectónicos incas en términos de la distribución funcional del espacio. La presencia de una hornacina trapezoidal y de abundante cerámica

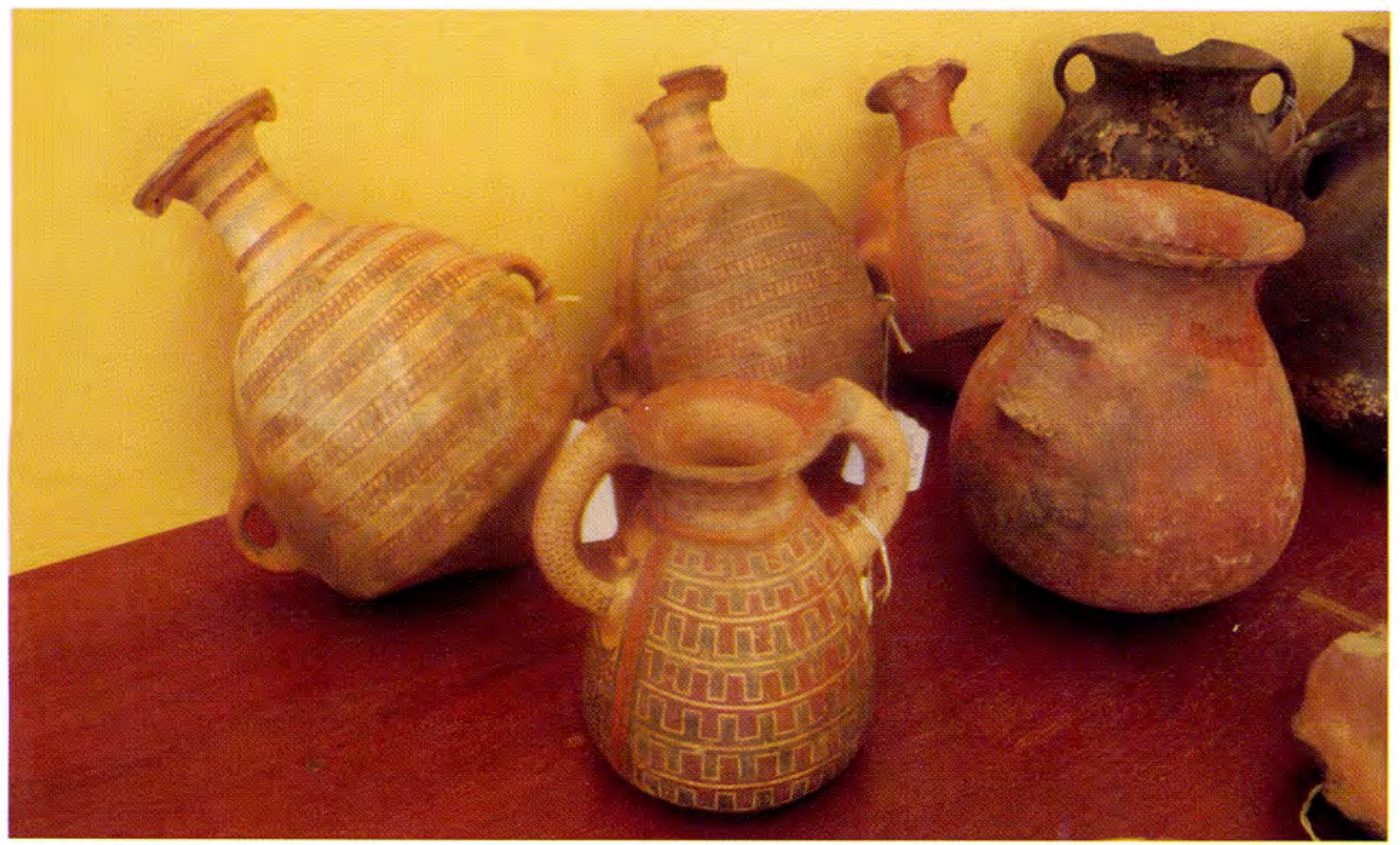

Moqi cerámica Inca 
incaica en la superficie, confirman este hecho. Se debe profundizar el análisis arquitectónico mediante la realización de excavaciones estratégicas tanto en las zonas disturbadas (recuperando, los perfiles originales] como en las que están sin disturbar, a fi i d e contestar los vacíos de investigación aún pendientes en el sitio.

\section{REFERENCIAS BIBLIOGRÁFICAS}

FLORES, Isabel (1969). Informe preliminar sobre las investigaciones arqueológicas en Tacna. En: Mesa Redonda de Ciencias Pre-históricas y Antropológicas. Instituto Riva-Aguero. Lima.

1983 Proyecto de Rescate e Investigación Arqueológica del "Cementerio Peañas". Informe mecanografiado e ilustrado presentado al INC-Tacna.

GORDILLO B, Jesús (1993) Catastro, inventario y evaluación de sitios arqueológicos del valle medio del Río Caplina, Tacna. Trabajo de Titulación Profesional de Licenciado en Arqueología, inédito. Universidad Católica Santa María, Arequipa.

1996 Desarrollo regional tardío y ocupación Inca en la pre-cordillera de Tacna. Ciencia y Desarrollo 3:96-111.

2000 Desde Tiwanaku hasta la ocupación Inka en el valle medio del Río Caplina, Tacna-Perú. Cultura y Desarrollo 2:83-108.

HIDALGO, Jorge y Calogero SANTORO [2001] El Estado Inca. En Pueblos del desierto entre el Pacífico y los Andes. pp. 72-84. Universidad de Tarapacá, Departamento de Arqueología y Museología, Arica.

MUÑOZ, Iván (1989). Perfil de la organización económico-social en la desembocadura del río Camarones: Períodos Intermedio Tardío e Inca. Chungara Revista de Antropología Chilena 22:85-111.

1998 La expansión incaica y su vinculación con las poblaciones de los valles occidentales del extremo norte de Chile. Tawantinsuyu 5:127-137.

MUÑOZ, Iván, Juan CHACAMA, Gustavo ESPINOZA y Luis BRIONES, 1987. La ocupación tardía en Zapahuira y su vinculación a la organización social y política inca. Chungara Revista de Antropología Chilena 18:67-89.

MUÑOZ, Iván y Juan CHACAMA, 1993. El Inca en la sierra de Arica. Actas del XII Congreso Nacional de Arqueología Chilena, Tomo I:269 284. Temuco.

ROMERO, Álvaro, 1999 Ocupación multiétnica en la sierra de Arica: Arquitectura, uso del espacio y distribución cerámica en el poblado arqueológico de Huaihuarani. En Boletín-e AZETA,documento electrónico,http://www.uta.cl/masma/a zeta/huaihua, accesado diciembre de 1999.

2005 Organización social y economía política en le prehistoria tardía de los valles de Arica (1100-1530 d.C.). Memoria de título, inédita. Departamento de Antropología, Universidad de Chile, Santiago. 
SANTORO, Calogero (1983). Camino del Inca en la Sierra de Arica. Chungara Nro 10:47-56. Universidad de Tarapacá, Arica-Chile.

SANTORO, C., ROMERO G., A. L., STANDEN, V., y TORRES, A (2004). Continuidad y Cambio en las Comunidades Locales, Periodos Intermedio Tardío y Tardío, Valles Occidentales del Área Centro Sur Andina. Chungara, Revista de Antropología Chilena 36, 235-247.

SANTORO, C., ROMERO G., A. L., STANDEN, V. , y VALENZUELA, D (2009). Interacción social en los periodos Intermedio Tardío y Tardío, Valle de Lluta, norte de Chile. En: Topic, J., (Ed.), La Arqueologia y la Etnohistoria: un encuentro andino. IAR Institute of Andean Research

SCHIAPPACASSE, Virgilio, Victoria CASTRO y Hans NIEMEYER (1989) Los Desarrollos Regionales en el Norte Grande (1.000 - 1.400 d.C.). En Culturas de Chile. Prehistoria. Desde los orígenes hasta los albores de la conquista, editado por Jorge Hidalgo, Virgilio Schiappacasse, Hans Niemeyer, Carlos Aldunate e Iván Solimano, pp. 181-220. Editorial Andrés Bello, Santiago de Chile.

TRIMBORN, Hermann (1975) Investigaciones arqueológicas en los valles del Caplina y Sama (Dpto. TacnaPerú). Studia Instituti Anthropos. Editorial verbo Divino.

UHLE, Max (1919) La Arqueología de Arica y Tacna. Boletín de la Sociedad Ecuatoriana de Estudios Históricos 3. Quito, Ecuador 1-48 pp.

VELA, Carlos (2004) La cerámica Cerro Los Hornos, presencia Inka en la costa de Tacna, sur de Perú. Chungara Revista Chilena de Antropología (Volumen Especial, Tomo II):935-942.

\section{Correspondencia}

Jesús Gordillo Begazo

goritumi@gmail.com

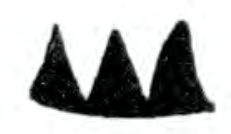

